\title{
Preparation of Selenium-rich Tea Set and Its Release Properties of Selenium in Water
}

\author{
Mingyu Di, ${ }^{1, \dagger}$ Xiang Chen, ${ }^{1, \dagger}$ Xiaoting Zhang, ${ }^{1}$ Ye Liu, ${ }^{1}$ Ilwoo Seok, ${ }^{2}$ Vignesh Murugadoss, $, 3,{ }^{*}$ Zhanhu Guo, ${ }^{4}$ Henry Colorado, ${ }^{5}$ Li \\ Meng, ${ }^{6}$ Dejian Tang ${ }^{6}$ and Bin Cui ${ }^{1, *}$
}

\begin{abstract}
In view of few systematic studies on selenium-rich ceramics, especially the controllable preparation, analysis, and characterization of selenium-rich ceramics, the release rule of selenium elements is rarely reported in the literature either. Therefore, this paper uses ordinary soil samples as raw materials to simulate the selenium-rich ceramics' synthesis by adding a selenium source to study the selenium content of selenium-rich ceramics and the dissolution law of selenium. With the increase in selenium added, the selenium content in selenium-rich ceramics increased from 13.3 to 112.4 ppm. When selenium pottery was soaked in water, the release amount of selenium was gradually increased with the extension of soaking time. With the increase of sintering temperature, the selenium content in selenium-rich ceramics was decreased from 30.1 to $18.2 \mathrm{ppm}$, and the selenium release amount was decreased from 0.13 to $0.06 \mathrm{ppm}$ when immersed in water for 48 hours. Therefore, by adding a selenium source, the selenium content in the selenium-rich ceramics can be controlled accurately and the leaching amount of selenium element is balanced and stable over time.
\end{abstract}

Keywords: Selenium; Ceramics; Sintering; Release properties.

Received date: 3 February 2021; Accepted date: 13 March 2021.

Article type: Research article.

\section{Introduction}

Since selenium's nutritional effect on animals was first discovered in 1957, people began systematic research on selenium and gradually found that selenium had a variety of beneficial biological effects. ${ }^{[1,2]}$ Selenium generally exists in both organic and inorganic forms in nature. Organic selenium exists as selenium methionine in the body and can participate in protein synthesis, which can be easily synthesized and absorbed in the body.[3] However, the method of

\footnotetext{
${ }^{I}$ College of Chemistry \& Materials Science, Northwest University, Xi'an, Shaanxi, 710127, China.

${ }^{2}$ Mechanical Engineering, Arkansas State University, Jonesboro, Arkansas, 72401, USA.

3 Advanced Materials Division, Engineered Multifunctional Composites Nanotech. LLC., Knoxville, 37934 USA.

${ }^{4}$ Department of Chemical \& Biomolecular Engineering, University of Tennessee, Knoxville, 37996, USA.

${ }^{5}$ Universidad de Antioquia UdeA, Calle $70 N^{\circ}$. 52-21, Medellín, Colombia.

${ }^{6}$ China Selenium Industry Research Institute, An' kang Shaanxi 725000, China.

*E-mail: cuibin@ nwu.edu.cn (Bin Cui); vigneshmurugadoss15@gmail.com (Vignesh Murugadoss)

${ }^{\dagger}$ These contributed equally to this work.
}

supplementing with organic selenium is very costly, and it is challenging to obtain synthetically. It cannot last for a long time to supplement the human body with trace element selenium. Inorganic selenium, which is selenium in the form of inorganic salts, has the disadvantage of being unsatisfactory in absorption and use, and excessive absorption is toxic. But due to its low cost and unique anti-tumor effect, it can be supplemented for the human body for a long time. ${ }^{[4]}$ Also, the biological half-life of selenium is 11 days, and its metabolism is quite fast. The human body must continuously supplement selenium to maintain the nutritional content of selenium in the body.

Therefore, using inorganic selenium to supplement selenium for a long time is of great significance. There are currently many ways of supplementing inorganic selenium, and mainly three significant categories are disease-oriented drugs, selenium-rich health foods, and selenium-rich daily necessities. Disease-oriented drugs such as hydroxyapatite (HAp) particles doped with selenite can effectively treat osteopathy. ${ }^{[5-7]}$ Selenium-rich health foods include Sodium tablets and Guiren selenium supplement tablets. Seleniumrich daily necessities such as selenium-rich pots, bowls, and cups are composed of selenium-rich ceramics materials. ${ }^{[8,9]}$ Among them, selenium-rich daily necessities can 
permanently and continuously supplement trace elements of selenium by soaking in water or food. Selenium-rich tea or selenium-rich foods can be selenium-supplemented by using selenium-rich ceramics daily necessities. This method allows organic selenium and inorganic selenium to work synergistically to better supplement selenium to the human body. ${ }^{[10]}$

At present, there are many patents available on seleniumrich ceramics, their preparation methods are different, and their characteristics are also different. ${ }^{[11,12]}$ The content of selenium released should be controlled, and it is not suitable for the human body for a long time to achieve the effect of selenium supplement. However, studies on the controllable preparation, analysis and characterization of selenium-rich ceramics, evaluation and analysis of selenium release, and their changing laws are rarely reported in the literature. Hence, it is a prerequisite to investigate the selenium release mechanism to supplement selenium in a controlled manner to satisfy our daily needs.

In this study, the ppm level of selenium addition was used to simulate selenium-rich ceramics' synthesis in the laboratory. In order to ensure the accuracy of selenium addition, a 100ppm selenium standard solution was prepared for addition according to national standards. The selenium-rich powders were prepared by mixing selenite standard solution as the selenium source with the ordinary clay sample by ball milling. A series of selenium-rich ceramics were designed by changing the selenium addition amount, sintering temperature and holding time of selenium-rich ceramics. The rule of selenium release in water was studied. By adding a selenium source to simulate the synthesis of selenium-rich ceramics, its preparation mechanism was explored, and the release of selenium was studied to lay a theoretical foundation for the controllable preparation of selenium-rich ceramics. X-ray diffraction (XRD) and scanning electron microscope (SEM) were used to characterize the phase structure and micromorphology of selenium-rich ceramics. Hydride generation atomic fluorescence spectrometry (HG-AFS) was used to analyze the selenium content in selenium-rich ceramics to discuss its preparation mechanism, selenium content, and selenium release rule of selenium-rich ceramics immersed in water.

\section{Experimental Section}

\subsection{Chemicals}

Anhydrous ethanol $\left(\mathrm{CH}_{3} \mathrm{CH}_{2} \mathrm{OH}, \geq 99.7 \%\right.$, purchased from Guangdong Guanghua Technology Co., Ltd.), Hydrofluoric acid (HF, $\geq 99.5 \%$, purchased from Tianjin Komio Chemical Reagent Co., Ltd.), Selenium powder (Se, $\geq 99.8 \%$, purchased from Tianjin Komio Chemical Reagent Co., Ltd.), Hydrochloric acid $(\mathrm{HCl}, \geq 37.5 \%$, purchased from Sichuan Xilong Science Co., Ltd.), Nitric acid $\left(\mathrm{HNO}_{3}, 68 \%-65 \%\right.$, purchased from Sichuan Xilong Science Co., Ltd.), Sodium borohydride $\mathrm{NaBH}_{4}, \geq 97.0 \%$, purchased from Chengdu Cologne Chemical Co., Ltd.) were used as received. The clay was obtained from Ankang, and the selenium content was very low. The composition of the clay was mainly quartz and kaolin.

\subsection{Sample preparation}

$100.0 \mathrm{mg}$ of selenium powders were weighed in a beaker and dissolved with $\mathrm{HNO}_{3}$. The solution was heated to dryness. To this, $2 \mathrm{~mL}$ of water was added and heated again to dryness again. The above processes were repeated 2-3 times. Then the residue was dissolved with $10 \% \mathrm{HCl}$ (volume fraction), which was transferred to a $1000 \mathrm{~mL}$ volumetric flask with $10 \% \mathrm{HCl}$ (volume fraction) and diluted to the mark, shaken well to obtain a 100 ppm selenite solution.

The clay samples of different quantities were ground and pulverized with different amounts of selenite solution. Then it was ball milled at $200 \mathrm{rpm}$ for $8 \mathrm{~h}$. The ball-milled mixed clay samples were placed in a $90{ }^{\circ} \mathrm{C}$ oven to remove residue water. The dried mixed samples were sieved, granulated and compressed, and sintered at different sintering temperatures (800-1200 ${ }^{\circ} \mathrm{C}$ ) in a protective atmosphere to obtain samples.

\subsection{Characterizations}

The phase structure of selenium-rich ceramics was tested using X-ray powder diffractometer (Bruker D8 Advance, Germany). The microstructure of selenium-rich ceramics was observed with a scanning electron microscope (Quanta-600, FEI, USA). The content of selenium after digestion of selenium pot and the content of selenium released in the water of selenium pot were analyzed by hydride-atomic fluorescence spectrometer (AFS-9130, Beijing Jitian Instrument Company, China). The apparent porosity of selenium-rich ceramics was measured using the Archimedes drainage method.

The selenium pottery was mixed with acid for digestion. The sample was dried, ground and crushed for digestion. After screening, $0.1 \mathrm{~g}$ of sample was added into a microwave digestion tank containing $2 \mathrm{~mL}$ of hydrofluoric acid, $10 \mathrm{~mL}$ of concentrated nitric acid, and $2 \mathrm{~mL}$ of hydrogen peroxide and kept undisturbed for $10 \mathrm{~min}$. Then the sample was put into the microwave digestion apparatus for digestion. After the digestion was completed, the microwave digestion tank was washed with nitric acid 3 to 4 times. The combined washing liquid was transferred to a beaker, placed on an electric hot plate and steamed to near dryness. Then $4.2 \mathrm{~mL}$ of hydrochloric acid was added and heated for 2 to 3 min until it becomes transparent. After cooling, the solution was transferred to a $50 \mathrm{~mL}$ volumetric flask and diluted with 1 $\mathrm{mol} / \mathrm{L}$ of hydrochloric acid to test the selenium content using hydride atomic fluorescence spectrometer. ${ }^{[13]}$

\section{Results and Discussion}

\subsection{Effects of selenium addition on microstructure and selenium release properties of selenium-rich ceramics samples}

The SEM images of selenium-rich ceramics with different amounts of selenium are shown in Fig. 1. It is observed that with the change of selenium content, the surface morphology 


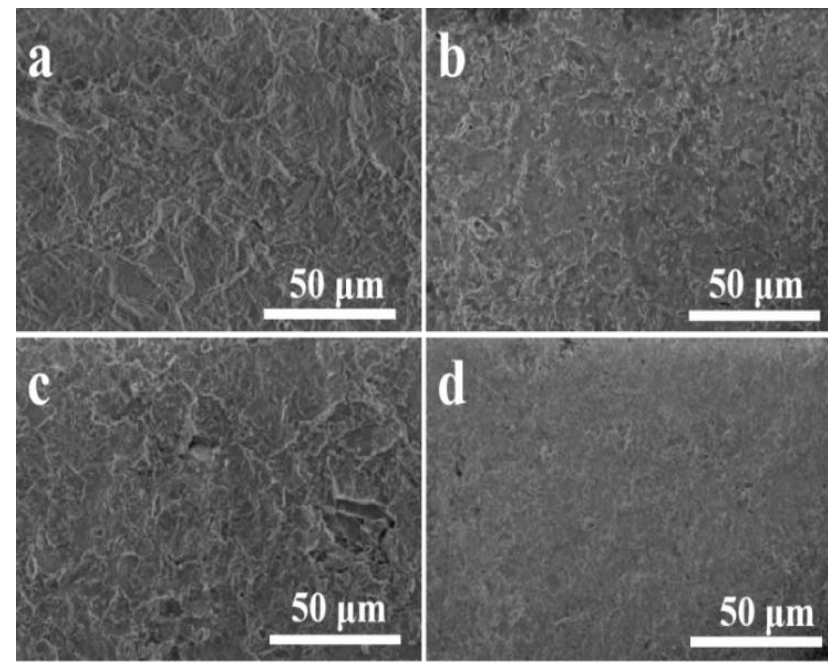

Fig. 1 SEM image of selenium-rich ceramics with different amounts of selenium sintered for $2 \mathrm{~h}$ at $1000{ }^{\circ} \mathrm{C}$ (a: $20 \mathrm{ppm}, \mathrm{b}: 40$ ppm, c: 100 ppm, d: 200 ppm).

of selenium-rich ceramics does not change significantly. The surface of the selenium-rich ceramics is smooth and compact, without obvious pore structure. These results reveals that the addition of selenium at the ppm level does not significantly change the main composition and structure of the seleniumrich ceramics themselves, and it is still mainly quartz. Therefore, different selenium additions will not change the microstructure of the selenium-rich ceramics.

Fig. 2 shows the XRD patterns of clay and selenium-rich ceramics with different amounts of selenium. It indicates that the clay is mainly composed of quartz phase and contains a small amount of kaolinite and hematite phase. After sintering, feldspar phase appears in the selenium-rich ceramics. Selenium-rich ceramics exhibit aluminosilicate crystal structures as dominant phase irrespective of selenium content.

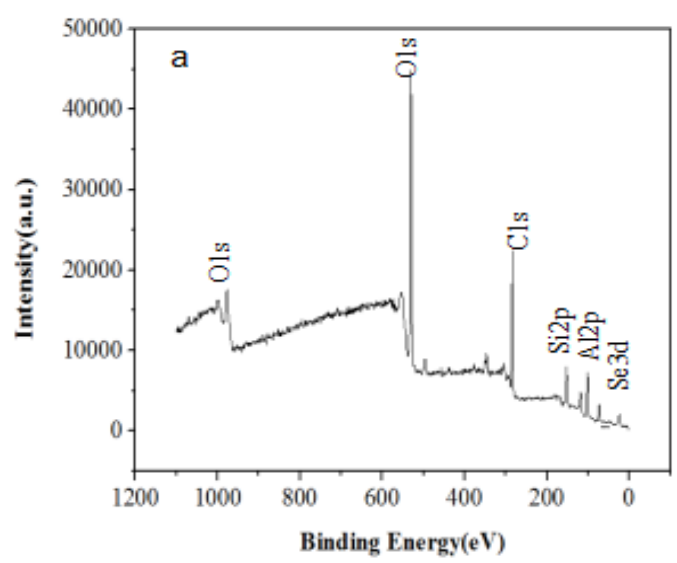

The peaks mainly correspond to quartz, feldspar, kaolinite, and hematite phases. Thus, the selenium content has little effect on the phase of selenium-rich ceramics, under the same sintering process. ${ }^{[14,15]}$

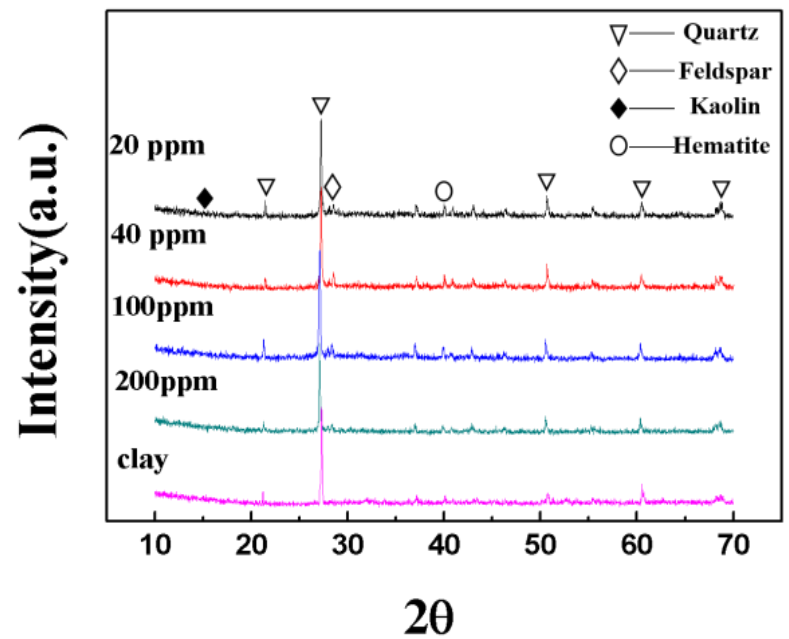

Fig. 2 XRD patterns of clay and selenium-rich ceramics with different amounts of selenium.

Fig. 3 shows the XPS diagram of selenium-rich ceramics. The prominent characteristic peaks of selenium-rich ceramics are $\mathrm{O}_{1 \mathrm{~s}}, \mathrm{C}_{1 \mathrm{~s}}, \mathrm{Si}_{2 \mathrm{p}}, \mathrm{Al}_{2 \mathrm{p}}$, and $\mathrm{Se}_{3 \mathrm{~d}}$, indicating that the primary constituent elements of selenium-rich ceramics are $\mathrm{Si}, \mathrm{Al}$, and $\mathrm{O}$. This result is also consistent with the corresponding aluminosilicate main crystal phase in XRD. It can also be observed from the spectrum of $\mathrm{Se}_{3 \mathrm{~d}}$ that there are prominent Se characteristic peaks at $61 \mathrm{eV}$ and $54 \mathrm{eV}$, which correspond to +6 and +4 valence selenium elements, respectively. ${ }^{[16]}$ The strong peak at $61 \mathrm{eV}$ indicates that the selenium element in the selenium-rich ceramics exists mainly at the valence state of +6 . $^{[16]}$

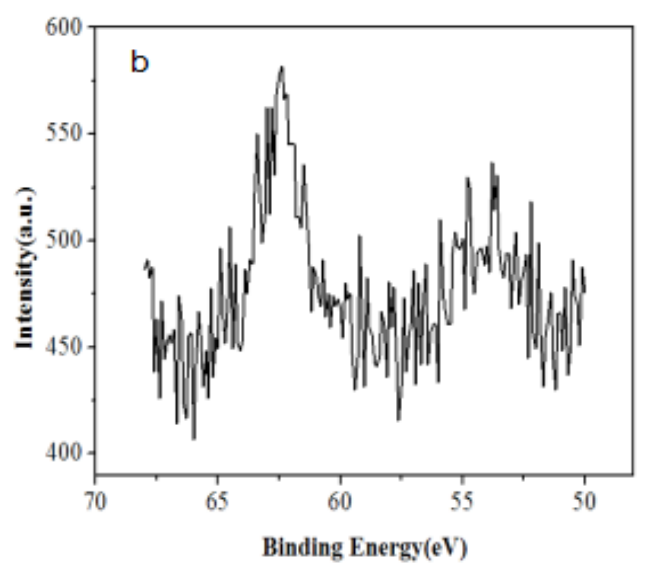

Fig. 3 XPS spectrum of selenium-rich ceramics: (a) total spectrum and (b) fine spectrum of Se3d.

Table 1 The apparent porosity and density of selenium ceramics with different amounts of selenium.

\begin{tabular}{ccccc}
\hline Different selenium amounts (ppm) & 20 & 40 & 100 & 200 \\
\hline Apparent porosity (\%) & 38.2 & 38.1 & 38.1 & 38.3 \\
\hline Density $\left(\mathbf{g . c m}^{-\mathbf{3}}\right)$ & 1.77 & 1.78 & 1.78 & 1.77 \\
\hline
\end{tabular}


Table 2 Theoretical and actual selenium content and a selenium loss percentage of selenium-rich ceramics with different selenium amounts.

\begin{tabular}{ccc}
\hline Different selenium amounts (ppm) & Actual selenium content (ppm) & Loss hundred fraction (\%) \\
\hline 20 & 13.3 & 33.5 \\
40 & 25.3 & 36.8 \\
100 & 64.6 & 35.4 \\
200 & 112.4 & 43.8 \\
\hline
\end{tabular}

It can be known from Table 1 that under the same sintering conditions, with the increase of the selenium addition, the apparent porosity of the selenium ceramics is basically around

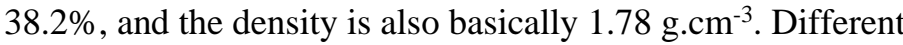
amounts of selenium added have almost no effect on the apparent porosity and density of selenium ceramics. This is because the addition of selenium at the ppm level does not significantly affect the composition and structure of selenium pottery.

The actual selenium content of selenium-rich ceramics increases gradually with the increase of selenium addition known from Table 2 . The loss percentage of selenium element is between $33.5 \%$ and $43.8 \%$, which shows that the loss of selenium is due to selenium's volatilization and decomposition at high temperatures.

Fig. 4(a) shows the release curve of the selenium concentration of selenium-rich ceramics with different amounts of selenium as a function of soaking time in the water. Test the release of selenium in selenium-rich ceramics within the range of $0 \sim 48 \mathrm{~h}$ soaking time. The release of selenium element from the selenium-rich ceramics gradually increased in 0-24 h, and gradually slowed after $24 \mathrm{~h}$. This is because the concentration difference of selenium element is relatively large at the beginning of the release, so the release is fast. As the concentration difference is gradually decreased, the release rate is slowed down and stabilized. The selenium concentration release curves of selenium-rich ceramics prepared from different selenium addition amounts after

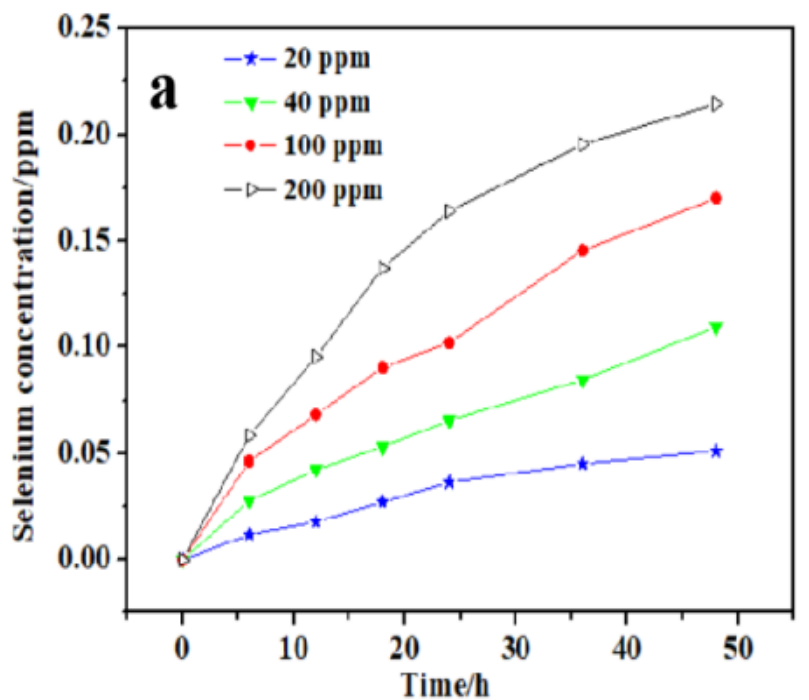

soaking in water for $48 \mathrm{~h}$ are shown in Fig. 4(b). It displays that the selenium release amount is $0.05 \mathrm{ppm}$ when the selenium addition amount is $20 \mathrm{ppm}$. And the amount of selenium released is increased to $0.21 \mathrm{ppm}$ as the selenium addition amount is increased to $200 \mathrm{ppm}$. It can be known that the amount of selenium released increases with increase in the amount of selenium added.

\subsection{Effect of sintering temperature on the microstructure and selenium release properties of selenium-rich ceramics samples}

Fig. 5 represents the SEM images of selenium-rich ceramics prepared at different sintering temperatures. At the sintering temperature of $800{ }^{\circ} \mathrm{C}$, the selenium-rich ceramics' surface is very rough, showing more pore structures. As the sintering temperature is increased, the selenium-rich ceramics' density is gradually increased, and the pore structure is gradually decreased. At $1200{ }^{\circ} \mathrm{C}$, the complex components of the selenium-rich ceramics' surface reacted to change, and some components have been melted, forming a smooth, dense and uniform texture. With the increase of the sintering temperature, the liquid phase structure is generated inside the selenium-rich ceramics, and the mass transfer process continues. The contact area between the particles increases, part of the pores gradually disappears, and the selenium-rich ceramics' density is also increased. Simultaneously, since the selenium-rich ceramics are mainly based on the aluminosilicate crystal structure, the main composition is quartz and contains many

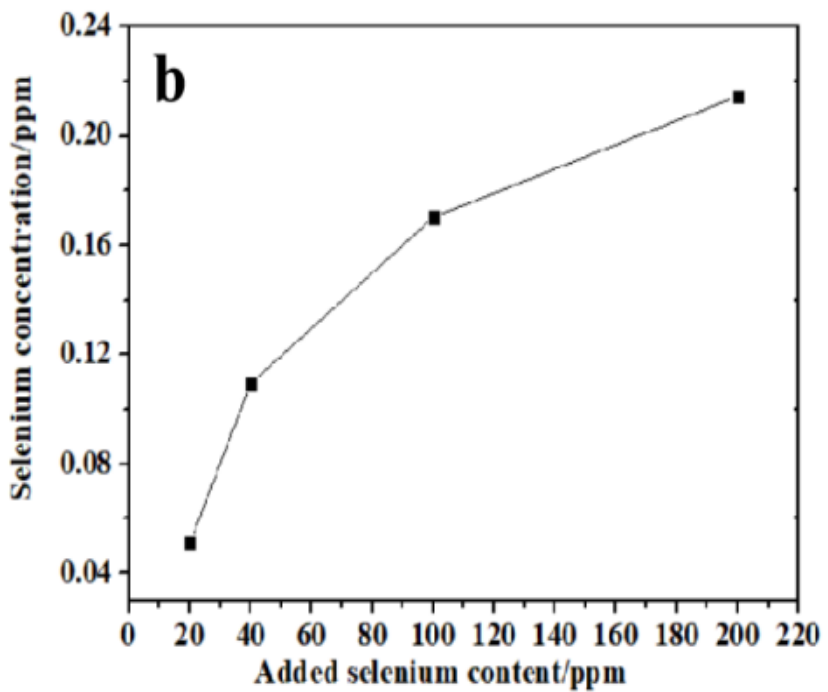

Fig. 4 Curve of the released selenium concentration in water of selenium-rich ceramics with different selenium contents (a) as a function of soaking time, (b) after soaking in water for $48 \mathrm{~h}$. 


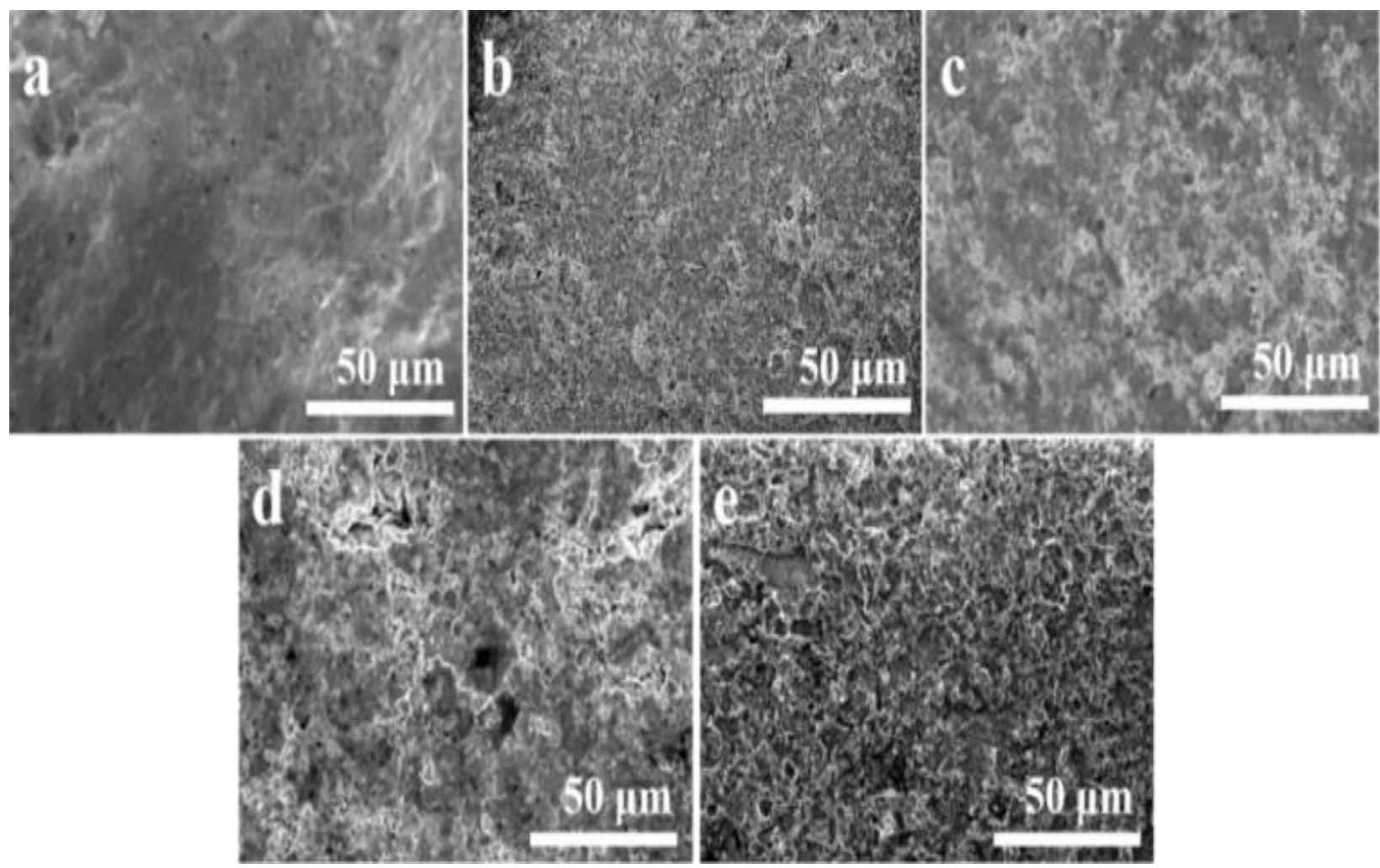

Fig. 5 SEM image of selenium-rich ceramics prepared at different sintering temperatures: (a: $1200^{\circ} \mathrm{C}$, b: $1100{ }^{\circ} \mathrm{C}$, c: $1000^{\circ} \mathrm{C}$, d: $900^{\circ} \mathrm{C}, \mathrm{e}: 800^{\circ} \mathrm{C}$ ).

other complex compounds. With the increase of temperature, various complex reactions will occur inside the selenium-rich ceramics. In this process, the selenium-rich ceramics becomes denser with the phase transition of quartz and the formation of many vitrified substances, which will effectively enhance the hardness of the selenium-rich ceramics framework. ${ }^{[17]}$

Because the ceramsite blank itself contains various components such as $\mathrm{Si}, \mathrm{Ca}, \mathrm{Na}, \mathrm{K}, \mathrm{Fe}$, etc., very complex compounds are generated. According to the XRD patterns of selenium-rich ceramics prepared at different sintering temperatures (Fig. 6), the selenium-rich ceramics are mainly dominated by aluminosilicate crystal structure with the peaks correspond to quartz, feldspar, kaolinite and hematite phases. As the temperature increases, the raw materials' reactants undergo ion replacement, crystal rearrangement, decomposition, redox and other reactions during the hightemperature sintering, forming some new minerals and components. ${ }^{[18]}$ It can also be observed that the diffraction peaks of kaolinite and other minerals gradually disappear with an increase in temperature. In contrast, the peak width of the characteristic peak gradually narrowed, and the crystallinity is improved. According to the analysis, at $1000{ }^{\circ} \mathrm{C}$, the kaolinite will be crystallized out of the crystal water to form a new crystal form, the diffraction peak position will change, and the content of quartz will gradually decrease, while the diffraction peak of feldspar will gradually increase. This shows that the amorphous material was formed by mixing and decomposing the quartz crystal phase. Other mineral phases slowly include the feldspar crystal phase. ${ }^{[19]}$ As the sintering temperature continues to increase, this process is accompanied by the formation of aluminosilicate, feldspar, and many vitrified substances, which enhances the strength of ceramsite. These formed mineral components also form the skeleton structure of selenium-rich ceramics to ensure that the prepared sample has a certain compression performance. Simultaneously, the content of added selenium is minimal, only at the ppm level, so the phase composition of selenium cannot be known from the XRD patterns.

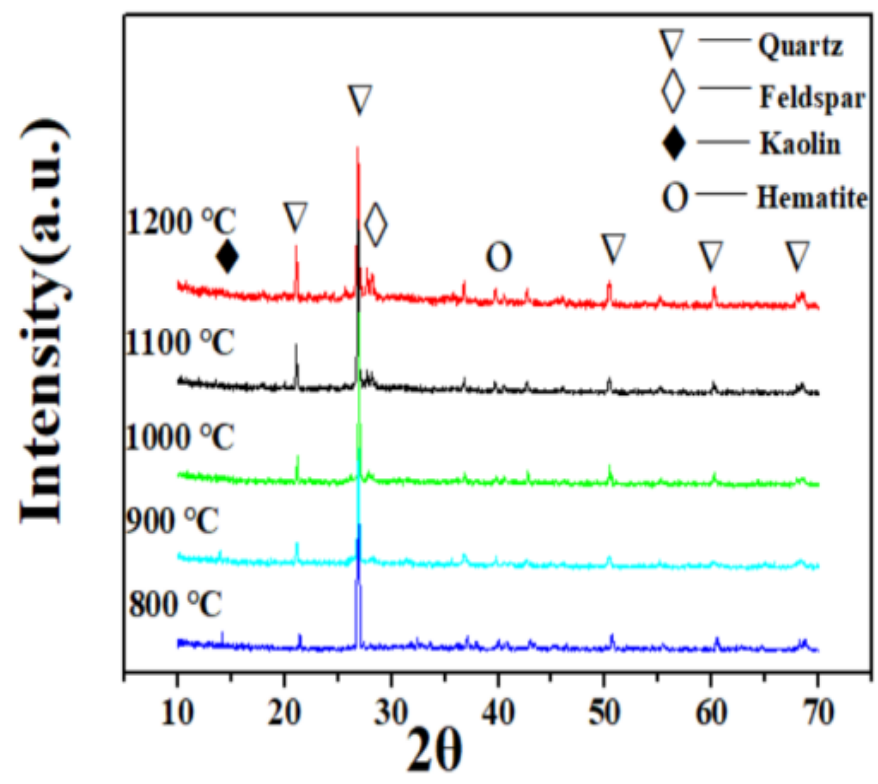

Fig. 6 XRD patterns of selenium-rich ceramics prepared at different sintering temperatures. 
Table 3 The apparent porosity and density of selenium ceramics prepared at different sintering temperatures.

\begin{tabular}{|c|c|c|c|c|c|}
\hline Sintering temperature $\left({ }^{\circ} \mathrm{C}\right)$ & 800 & 900 & 1000 & 1100 & 1200 \\
\hline Apparent porosity $/ \%$ & 42.1 & 39.6 & 38.1 & 36.3 & 32.5 \\
\hline Density/g.cm ${ }^{-3}$ & 1.65 & 1.72 & 1.78 & 1.83 & 1.92 \\
\hline
\end{tabular}

It can be seen from Table 3 that as the sintering temperature increases, the apparent porosity of selenium ceramics decreases from $42.1 \%$ at $800^{\circ} \mathrm{C}$ to $32.5 \%$ at $1200^{\circ} \mathrm{C}$, and the density of selenium ceramics increases from $1.65 \mathrm{~g} . \mathrm{cm}^{-3}$ at $800^{\circ} \mathrm{C}$ to $1.92 \mathrm{~g} \mathrm{g.cm}^{-3}$ at $1200^{\circ} \mathrm{C}$. This may be because the main component of selenium-rich ceramics is a complex compound dominated by quartz. With the increase of temperature, selenium-rich ceramics undergoes various reactions such as decomposition, ion replacement and redox, accompanied by the formation of aluminosilicate, feldspar and a large amount of vitrified substances, enhances the compactness of seleniumrich ceramics, so that the apparent porosity of selenium-rich ceramics gradually decrease and the density gradually increase, which is also consistent with the results of XRD and SEM.

It can be seen from Table 4 that the selenium content of selenium-rich ceramics gradually increases with the increase of sintering temperature; especially when the temperature rises to $1200{ }^{\circ} \mathrm{C}$, the selenium content decreases sharply by $54.5 \%$. This is attributed to the complex reaction between the added selenite and the compounds inside the selenium-rich ceramics during the sintering process. At higher temperatures, the
$\mathrm{SeO}_{3}{ }^{2-}$ will be decomposed and volatilized to cause selenium loss. ${ }^{[20]}$

It can be seen from Fig. 7(a) that the released selenium Content of selenium-rich ceramics samples prepared at different sintering temperatures gradually increased with the increase of the soaking time. Fig. 7(b) shows the change curve of selenium concentration of selenium-rich ceramics prepared at different sintering temperatures immersed in water for $48 \mathrm{~h}$ in Fig. 7(b). It is observed that the selenium release amount of selenium-rich ceramics prepared by sintering at $800{ }^{\circ} \mathrm{C}$ for 48 $\mathrm{h}$ in water is $0.13 \mathrm{ppm}$. At $1200{ }^{\circ} \mathrm{C}$, the release of selenium was reduced to $0.06 \mathrm{ppm}$. It can be found that the release of selenium is gradually decreased with the increase of the sintering temperature of the selenium-rich ceramics sample. On one hand, due to the increase in the sintering temperature of the selenium-rich ceramics, the loss of selenium in the selenium-rich ceramics is increased, which reduces the amount of selenium released. The formation of aluminosilicates, feldspars, and a large number of vitrified substances enhances the density of selenium-rich ceramics so that the porosity of selenium-rich ceramics will be gradually

Table 4 Theoretical Selenium content, actual selenium content and loss percentage of selenium in selenium-rich ceramics prepared at different sintering temperatures.

\begin{tabular}{cccc}
\hline $\begin{array}{c}\text { Sintering } \\
\text { temperature }\left({ }^{\circ} \mathbf{C}\right)\end{array}$ & $\begin{array}{c}\text { Theoretical Selenium } \\
\text { content }(\mathbf{p p m})\end{array}$ & $\begin{array}{c}\text { Actual selenium content in } \\
\text { selenium-rich ceramics } \\
(\mathbf{p p m})\end{array}$ & $\begin{array}{c}\text { Loss percentage of } \\
\text { selenium }(\%)\end{array}$ \\
\hline $\mathbf{8 0 0}$ & 40 & 30.1 & 24.8 \\
$\mathbf{9 0 0}$ & 40 & 27.8 & 30.5 \\
$\mathbf{1 0 0 0}$ & 40 & 25.5 & 36.3 \\
$\mathbf{1 1 0 0}$ & 40 & 21.8 & 45.5 \\
$\mathbf{1 2 0 0}$ & 40 & 18.2 & 54.5 \\
\hline
\end{tabular}
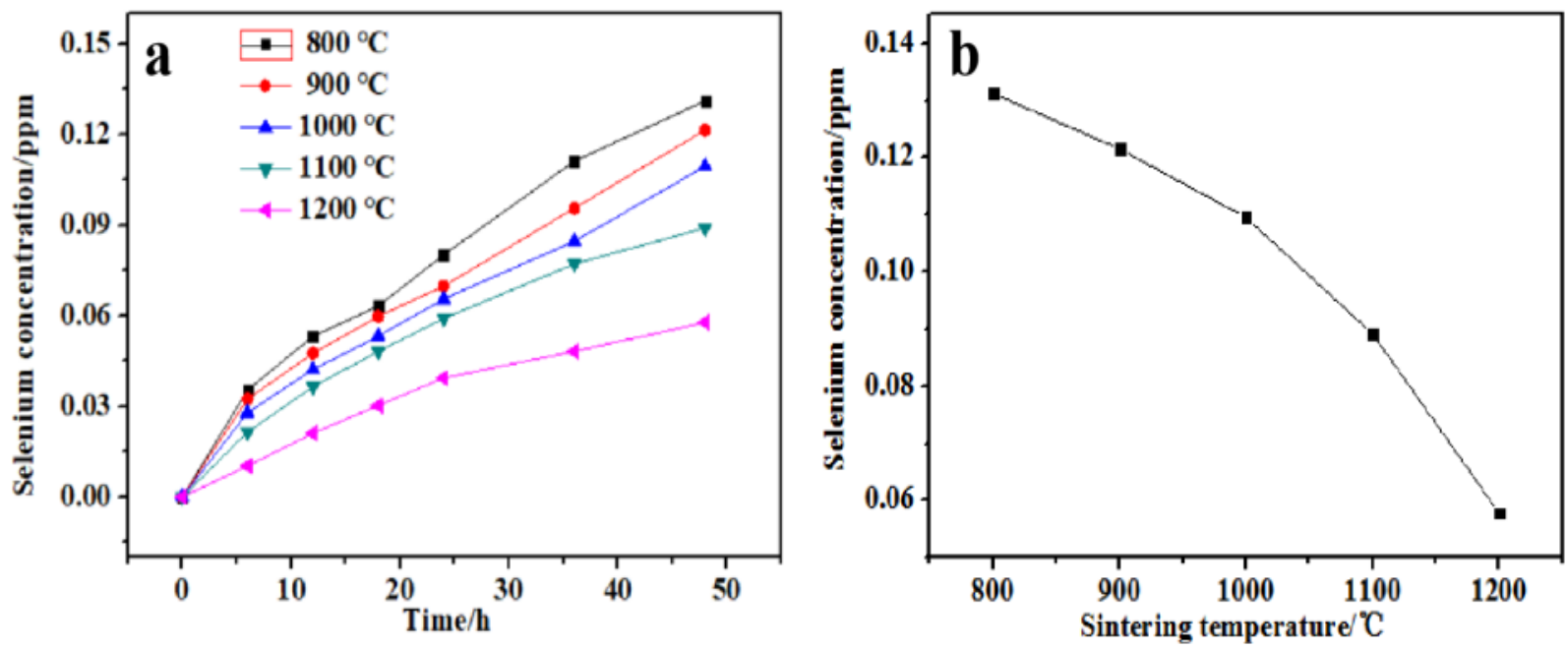

Fig. 7 Curve of the released selenium concentration in water of selenium-rich ceramics prepared at different sintering temperatures (a) as a function of soaking time, (b) after soaking in water for $48 \mathrm{~h}$. 
decreased. ${ }^{[21]}$ This leads to a reduction in the contact area between the selenium-rich ceramics and the water sample, which reduces selenium's ability to diffuse and release in water.

\section{Conclusions}

In this work, the common clay sample powder was mixed with the selenium source and the green body was sintered to obtain selenium-rich ceramics by the traditional sintering method, which laid the experimental foundation for the controlled synthesis of selenium-rich ceramics. The effects of selenium content and sintering temperature on the chemical composition, phase and micro-morphology of selenium-rich ceramics, as well as on the release performance of selenium in water were studied. The results revealed that with the increase in selenium, the selenium content in selenium-rich ceramics was increased from 13.3 to $112.4 \mathrm{ppm}$. Simultaneously, the amount of selenium released when soaked in water gradually was raised with the extension of the soaking time. The change of sintering temperature affected the densification degree and apparent porosity of the selenium-rich ceramics sample. The selenium content in the selenium-rich ceramics reduced from 30.1 to $18.2 \mathrm{ppm}$ with increased sintering temperature. The selenium release amount of the selenium-rich ceramics immersed in water for $48 \mathrm{~h}$ reduced from 0.13 to $0.06 \mathrm{ppm}$. In summary, it is suggested that the selenium addition amount should be 40ppm in the preparation process of selenium-rich ceramics, and the sintering temperature should be lower than $1000{ }^{\circ} \mathrm{C}$ to ensure that the selenium loss in the sintering process is less, and the selenium content in water is less than $0.005 \mathrm{ppm}$ in a short soaking time. This method can accurately control the selenium content in selenium-rich ceramics, and the selenium element in the selenium-rich ceramics can be automatically dissolved when immersed in water. The rule of selenium element dissolution with time is evident and balanced and stable and can be released slowly for a long time.

\section{Acknowledgments}

We thank the National Natural Science Foundation of China (Grant No. 21071115), the Shaanxi Natural Science Foundation (Grant No. 2020JZ-44), and Key Laboratory of Se-enriched Products Development and Quality Control, Ministry of Agriculture and Rural Affairs/ National-Local Joint Engineering Laboratory of Se-enriched Food Development (Grant No. Se-2020A01) for funding our research.

\section{Conflict of Interest}

There is no conflict of interest.

\section{Supporting Information}

Not applicable

\section{References}

[1] K. Schwarz, J. G. Bieri, G.M. Briggs, M.L Scott, Exp. Biol. Med., 1957, 95, 621-625, doi: 10.3181/00379727-95-23308.
[2] J. Pinsent, Biochem. J., 1954, 57, 10-16, doi: 10.1042/bj0570010.

[3] L. Zhang, X.R. Liu, J.Z. Liu, X.P. An, Z.Q. Zhou, B.Y. Cao, Biol. Trace Elem. Res., 2017, 183, 1-7, doi: 10.1007/s12011-0171112-1.

[4] D.P. Marta, C.M. Cristina, S.A. Ali, Int. J. Food Sci., 2017, 2017, 7613069, doi: 10.1155/2017/7613069.

[5] J. Ma, Y. Wang, L. Zhou, S. Zhang, Mater. Sci. Eng. C, 2013, 33, 440-445, doi: 10.1016/j.msec.2012.09.011.

[6] L.P. Belle, P.E.R. Bitencourt, F.H. Abdalla, R.B. Guerra, C. Funchal, M.B. Moretto, Chem.-Biol. Interact., 2011, 189, 141145, doi: 10.1016/j.cbi.2010.12.010.

[7] V. Uskokovic, M.A. Iyer, V.M. Wu, J. Mater. Chem. B, 2017, 5, 1430-1445, doi: 10.1039/C6TB03387C.

[8] Y.G. Lan, B.C. Lan. (China, 2019), chap. CN110372323A, pp CN110372323A

[9] Y. Yuan. (China, 2018), chap. CN108083764A, pp. CN108083764A.

[10] X.R. Huo. (China, 2016), chap. CN105541406A, pp. CN105541406A.

[11] J.D. Cui. (China, 2003), chap. CN2595272, pp. CN2595272. [12] X.L. Xu. (China, 2012), chap. CN202619141U, pp. CN202619141U.

[13] N. Zhang, G. Sun, H. Ma, Miner. Eng., 2007, 20, 1397-1400, doi: 10.1016/j.mineng.2007.09.001.

[14] X. R. Liu, L. Xiong, A. Y. Chen, Adv. Mat. Res., 2012, 1571, 195-198, doi: 10.4028/www.scientific.net/AMR.412.195.

[15] F. L. Liu, Y. L. Yang, Q. B. Chang, Z.W. Hu, Y. Q. Wang, Chn. Ceram. ind., 2019, 26, 21-25, doi: 10.13958/j.cnki.ztcg.2019.02.005.

[16] O. Adegoke, P. Mashazi, T. Nyokong, P. B. C. Forbes, Opt. Mater., 2016, 54, 104-110, doi: 10.1016/j.optmat.2016.02.024.

[17] G. R. Xu, J. L. Zou, G.B. Li, J. Hazard. Mater, 2008, 150, 394-400, doi: 10.1016/j.jhazmat.2007.04.121.

[18] M. Liu, C. Wang, Y. Bai, G. Xu, J. Alloy. Compd., 2018, 748, 522-527, doi: 10.1016/j.jallcom.2018.03.216.

[19] Z. Fan, Master, Yangzhou University, Jiangsu, 2015.

[20] L.X. Wei, Master, South China University of Technology, Guangzhou, 2018.

[21] L. Han, Master, Zhengzhou University, Zhengzhou, 2018.

\section{Author information}

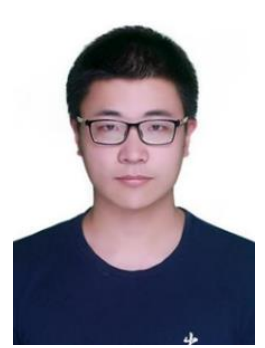

Mingyu Di is currently studying at Northwestern University School of Chemistry and Materials Science. His research direction is the preparation of selenium-rich ceramic materials and the study of selenium release performance of it. 


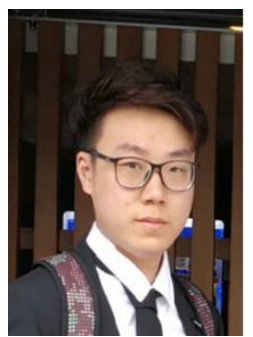

Xiang Chen graduated from the School of Chemistry and Material Science at Northwestern University, where he was mainly engaged in the preparation of selenium-rich ceramics and the research of selenium release.

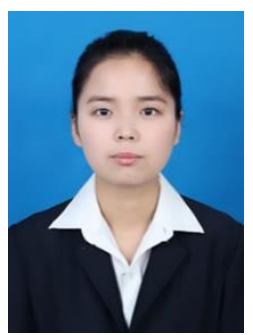

Xiaoting Zhang is currently studying for her PhD at Northwestern University School of Chemistry and Materials Science. She is mainly engaged in study on preparation and energy storage mechanism of sodium bismuth titanate-based energy storage ceramic materials.

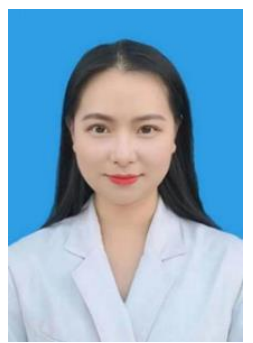

Ye Liu is currently studying for her PhD at Northwestern University School of Chemistry and Materials Science. Her research direction is design and research of properties of microwave-absorbed inorganic multifunctional nanomaterials based on Janus mesoporous $\mathrm{SiO}_{2}$.

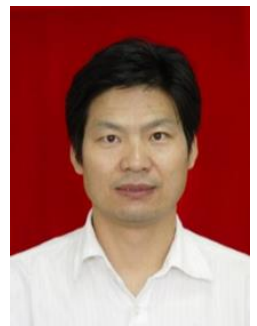

Bin Cui, professor and doctoral supervisor of the Department of Chemistry of Northwest University, is engaged in the synthesis, characterization and application of nanomaterials, and the preparation and application of functional ceramic materials.

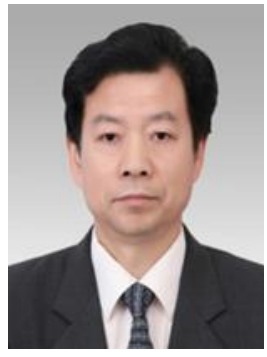

Dejian Tang, senior agronomist, director of Ankang Se-enriched Product $R \& D$ Center, director of Key Laboratory of Seenriched Product Development and Quality Control of Ministry of Agriculture and Rural Affairs, is engaged in scientific research and industrialization of selenium-enriched industry.

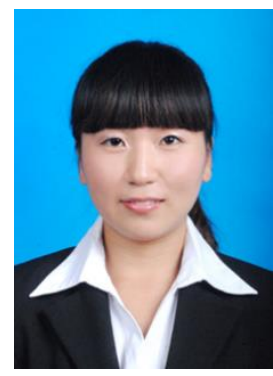

Li Meng, an agronomist, works at the Ankang Se-enriched Product R\&D Center. She is engaged in research on the development of Se-enriched products and the detection of functional ingredients in food.

Publisher's Note Engineered Science Publisher remains neutral with regard to jurisdictional claims in published maps and institutional affiliations. 